\title{
Currículo e Competências
}

\section{Curriculum and Competences}

\author{
Ruy César Pietropaoloab; Samira Fayes Kfouri da Silva ${ }^{\mathrm{b}}$
}

\begin{abstract}
${ }^{a}$ Universidade Anhanguera de São Paulo, Programa de Pós-Graduação Stricto Sensu em Educação Matemática. SP, Brasil. bUnopar, Programa de Pós-Graduação Stricto Sensu em Metodologias para Ensino de Linguagens e suas Tecnologias. PR, Brasil. E-mail: samira.kfouri@kroton.com.br
\end{abstract}

\begin{abstract}
Resumo
Neste artigo são discutidos significados da palavra Competência, presentes em muitos discursos de educadores e de profissionais de outras áreas. Muitas vezes, essa palavra é utilizada de forma redutora, associando-a ao saber-fazer, mas sem enfatizar outras dimensões como conhecimentos, habilidades cognitivas e atitudes. Esta é uma pesquisa teórica, pois na ação de buscar os significados do conceito de competência foi preciso fazer uma análise de muitos artigos, cujas temáticas se aproximam do saber e do saber-fazer. Apresentam-se as concepções de competência de Perrenoud, de Lino de Macedo e da Base Nacional Comum Curricular com o objetivo de desenvolver uma breve reflexão sobre o currículo por competências para o Ensino Superior, questionando suas possiblidades frente a um currículo centrado em conteúdos disciplinares. O currículo por competências, que também pressupõe um sistema multidimensional de ensino, implica necessariamente em uma reinvenção do papel do professor, distanciando-se de um modelo convencional - professor da sala de aula - para tornar-se membro de um grupo multitalentoso. Nesse sentido, são apresentadas neste texto algumas competências necessárias para esse docente como a de saber criar centros de interesse para os alunos adultos, explorando situações de aprendizagem em torno das quais organizará os objetos de aprendizagem expressos nas competências profissionais a serem desenvolvidas.
\end{abstract}

Palavras-chave: Competência. Currículo por Competência. Formação de Professores.

\begin{abstract}
This article discusses the meanings of the word Competence, present in many speeches by educators and professionals from other areas. This word is often used in a reductive way, associating it with know-how, but without emphasizing other dimensions such as knowledge, cognitive skills and attitudes. This is a theoretical research, because in the search for the meanings of the concept of competence, it was necessary to analyze many articles whose themes are close to knowledge and know-how. Perrenoud, Lino de Macedo and the National Common Curricular Base conceptions of competence are exhibited in order to develop a brief reflection on the competency curriculum for higher education, questioning its possibilities in before a curriculum centered on disciplinary content. The competency curriculum, which also presupposes a multidimensional teaching system, necessarily implies a reinvention of the teacher's role, moving away from a conventional model - classroom teacher - to become a member of a multitalented group. Thus, this text shows some skills necessary for this teacher, such as knowing how to create interest centers for adult students, exploring learning situations around which to organize the learning objects expressed in the professional skills to be developed.
\end{abstract}

Keywords: Competence. Curriculum by Competence. Teacher Education.

\section{Introdução}

É fato incontestável que as discussões sobre as aprendizagens dos estudantes de cursos da Educação Superior devem ser ampliadas e aprofundadas, não apenas decorrente do atual perfil dos egressos do Ensino Médio - jovens e adultos -, mas também de pesquisas e estudos sobre novas estratégias educacionais, novas atitudes frente ao conhecimento, competências e habilidades, inovações nos processos de formação de professores, o ensino híbrido e sobre relações entre estudantes e professores.

Neste artigo são discutidas questões sobre currículos por competência no Ensino Superior. Assume-se, por um lado, a multiplicidade de significados do conceito de competência, considerando sua divulgação, de forma consistente, no
Brasil, no final da década de 1990 e, por outro, a relevância do papel do professor para determinar o sucesso ou não da implementação de inovações, tendo em vista que ele é um dos agentes fundamentais para o currículo praticado se aproximar do currículo prescrito.

Aborda-se, especificamente, currículo por competências, aliando experiências e estudos sobre andragogia às práticas desenvolvidas pela Instituição para a formação dos estudantes, compreendendo as possibilidades de inovações serem materializadas na perspectiva de contribuir para a concepção de um currículo em ação, construído a partir da participação coletiva e para a realidade.

Compreende-se que no desenvolvimento de um currículo deveriam estar manifestas as necessidades e as escolhas 
de competências, de conhecimentos, de habilidades e de atitudes necessárias para responder ao processo dinâmico das exigências profissionais, na atualidade, cada vez mais complexas. Um currículo, neste contexto, precisa traduzir essas exigências, tão diversificadas e, no caso brasileiro, ainda mais acentuadas.

Para desenvolver este estudo se conta com um levantamento de práticas em outros países, com predominância andragógica, de relevância quanto à cultura e, principalmente, quanto ao próprio desenvolvimento e exigências econômicas, avanços tecnológicos em marcha e formação profissional. A ideia prevalente para a análise desses estudos foi a de repensar o currículo desta Instituição, sem cair em praticismo, identificando teorias consistentes para introduzir inovações, (re)definir finalidades e competências, a partir da análise de práticas profissionais e inseridas na realidade social.

Segundo Moore (2016), os educadores têm como desafio o envolvimento dos estudantes adultos no gerenciamento de seu próprio aprendizado, pois se trata de uma característica definidora da andragogia: acreditar que a maioria desses estudantes deve ter competência e/ou vontade de participar ativamente de seu próprio aprendizado.

\section{Desenvolvimento}

\subsection{Metodologia}

Esta é uma pesquisa de cunho teórico e bibliográfico. Teórico, pois na ação de investigar as oscilações de significados de conceitos como competências, habilidades, atitudes, conhecimentos, conteúdos disciplinares ou interdisciplinares, depende-se de uma coleta de dados, com o destaque que esses são opiniões, noções, conceitos ou categorias que precisam ser discernidas como também identificar no que se interpenetram, segundo uma perspectiva metodológica. Foi necessário analisar as matrizes teóricas que tecem as relações e variações de significados dos termos que se propõe a investigar.

Para superar conflitos entre diferentes vertentes se utiliza uma abordagem complementarista, metodologicamente calcada de que as concepções de competência teórica de Perrenoud, da BNCC e das utilizadas na linguagem do mercado, podem ser complementares ainda que haja idiossincrasias. A complementaridade, por um lado, complementa as relações entre os objetos de conhecimentos e de competências (aspectos estruturais e intencionais) e, por outro, ressalta a necessidade de identificação das diferenças entre esses objetos e competências no âmbito das aplicações ou modelos (aspectos extensionais).

Esta pesquisa também tem cunho bibliográfico, pois decorre de pesquisas anteriores, em documentos impressos, como: livros, artigos, teses etc. Utiliza- se de dados ou de categorias teóricas já trabalhadas por outros pesquisadores. $\mathrm{O}$ pesquisador trabalha a partir das contribuições dos autores dos estudos analíticos constantes dos textos (SEVERINO, 2007, p. 122).

\subsection{Sobre currículos por competências}

O Conselho Nacional de Educação, por meio da Câmara de Educação Superior, instituiu Diretrizes Curriculares para os cursos de graduação, a partir de 2001. Esses documentos procuram assegurar às Instituições de Ensino Superior ampla liberdade na escolha e especificação das disciplinas a serem ministradas e na composição da carga horária a ser cumprida para a integralização dos currículos. Assim, deixam de indicar disciplinas obrigatórias e optativas, presentes em legislações anteriores, mas apresentam um conjunto necessário de competências/habilidades/atitudes e o perfil do egresso/ profissional.

Segundo o item II do Parecer 583/2001, verifica-se que, apesar de esses documentos contemplarem a natureza e as peculiaridades de cada curso de graduação (habilitações e ênfases), algumas das diretrizes são obrigatórias e, portanto, comuns a todos, pois além das competências e o perfil do egresso, indicam também acompanhamento e avaliação.

Essa discussão, não tão nova, sobre currículos por competências faz sentido, porquanto esta Instituição tem por objetivo a formação do estudante para o mundo do trabalho, requerendo hoje do sujeito não apenas competências específicas, mas, sobretudo, a de aprender a aprender para se desenvolver, profissionalmente, de modo a atender as demandas cada vez mais complexas da vida cotidiana e profissional.

O conceito de competência, proveniente de contexto empresarial, foi inicialmente introduzido na escola em nível de formação profissional, mediante a conjuntura de pressões do mercado de trabalho (ROLDÃO, 2003). Este discurso se relaciona com a valorização de uma aprendizagem contextualizada e em ação, em resposta às rápidas transformações dos saberes e das práticas profissionais.

No entanto, qual é o significado de Competência? Esse conceito tem tanto eco em educadores de raiz comportamentalista como também nos construtivistas, e se reveste de múltiplos significados, cuja abrangência abarca uma pluralidade de definições, veiculando noções sujeitas à diversidade de acepções e até mesmo ambivalentes.

Portanto, competência é um termo polissêmico. Alguns interpretam competência como condição prévia do sujeito, que poderia ser também herdada e não apenas desenvolvida a pessoa teria dom. Outros tendem a considerar competência como condição dada por objetos e não pelo sujeito. Na escola, essa forma está presente, por exemplo, quando um professor é julgado pelas tecnologias que utiliza, pela qualidade de provas que aplica e rigor de correção, pelo status do livro que adota, pela Universidade que estudou. Outro significado de competência é considerá-la interdependente; não basta o sujeito ser um conhecedor de um assunto, não basta possuir materiais potentes e adequados, pois o importante é como esses fatores interagem. Esse modo de ver e conceber esse conceito é denominado de Competência Relacional, expressa 
por esse jogo de interações (MACEDO, 2005).

Quando se adiciona o termo habilidades às competências, o conflito entre significados se amplia. Muitos fazem distinção entre esses dois termos, outros os consideram como sinônimos e usar junto seria redundância. Há, ainda, aqueles que utilizam essas palavras sempre juntas, como se complementassem ou, talvez, por ser difícil diferenciá-las exatamente uma da outra.

Por outro lado, no mundo corporativo, parece haver certo consenso sobre significado de competência, compreendendo, necessariamente, três elementos: conhecimentos, habilidades e atitudes. Os conhecimentos do sujeito seriam os conhecimentos adquiridos/construídos em sua formação acadêmica, em vivências cotidianas e em práticas profissionais. As habilidades seriam as capacidades de colocálos em prática, o saber fazer. As atitudes seriam a capacidade de tomar iniciativas para transformar ou melhorar o ambiente organizacional.

Segundo Perrenoud (1999), a definição de competência tem quatro aspectos: as competências não são elas mesmas, saberes, saber fazer ou atitudes, mas mobilizam, integram e orquestram esses recursos. A mobilização só é pertinente em ação e cada situação é particular, mesmo que se possa tratá-la por analogia com outras, já identificadas.

A Base Nacional Comum Curricular - BNCC, documento de caráter normativo, que prescreve o conjunto de aprendizagens essenciais de todos os alunos da Educação Básica, define competência como a mobilização de conhecimentos (conceitos e procedimentos), habilidades (práticas cognitivas e socioemocionais), atitudes e valores para resolver demandas complexas da vida cotidiana, do pleno exercício da cidadania e do mundo do trabalho. Essa definição da BNNC considera competência como unidade que abarca conhecimentos, habilidades e atitudes, congregando a ideia de competência como a constituinte de uma unidade de ensino, em que os elementos isolados perdem esse sentido.

Le Boterf (2005), ao discernir competência desenvolvida por um indivíduo particular de competência requerida, considera competência como processo e como produto. Segundo esse autor, a competência real, individual, está baseada em esquemas operativos descritos por autores ligados à Psicologia Cognitiva, por exemplo Ausubel (2000). Esses esquemas seriam permanentemente atualizados, integrando inovações e adaptando contextos. A competência prescrita, por sua vez, é da ordem dos produtos, do observável.

Longe da pretensão de discutir, neste texto, as diferentes concepções de competência, apresenta-se uma síntese, ainda que provisória desse conceito, mas adequado ao Ensino Profissional: competência operacional - knowing how, cujo destaque está no saber-fazer e no desempenho; competência acadêmica - knowing that, relacionada à construção de conhecimentos e ao desenvolvimento de estruturas cognitivas e de saberes metacognitivos; competência metodológica, transversal, acionada ao aprender a aprender e ao saber relacionar (Pacheco, 2005).
Um currículo baseado em competências deve envolver essas dimensões citadas, pois determina o que os estudantes deverão "saber fazer" e as atitudes a serem desenvolvidas ao final de um ciclo e não apenas, embora importante, o conhecimento de fatos, de conceitos e de procedimentos sobre um dado tema. Segundo Macedo (2005, p.2):

até pouco tempo, a grande questão escolar era a aprendizagem - exclusiva ou preferencial - de conceitos. Hoje, essa forma de competência continua sendo valorizada, principalmente, no meio universitário. Mas, com todas as transformações tecnológicas, sociais e culturais, uma questão prática, relacional, começa a impor-se com grande evidência. Temos muitos problemas a resolver, muitas decisões a tomar, muitos procedimentos a aprender. Isso não significa, obviamente, que dominar conceitos deixou de ser importante. Esse tipo de aula, insisto, continua tendo um lugar, mas cada vez mais torna-se necessário também o domínio de um conteúdo chamado de procedimental, ou seja, da ordem do saber como fazer.

Um dos pressupostos de um currículo por competências é a redefinição do papel dos objetos de conhecimento, os conteúdos. Nessa concepção de currículo, são as competências que os definem e não o contrário. Um exemplo: a disciplina álgebra linear, presente em Cursos de Engenharia é planejada, em geral, para ensinar conceitos e procedimentos que a estruturam e, somente depois, as aplicações são apresentadas aos estudantes, isso quando ocorre. Ainda que alguns professores procurem indicar competências para essa disciplina, muitos as definem a partir de uma lista prévia de conteúdos, linearmente concebida e, historicamente, construída. Se essa lógica for invertida, alguns conteúdos da lista podem ser enfatizados, outros minimizados e até dispensados, mas certamente os objetos ensinados ganhariam significado para o estudante, pois as aplicações não estariam apenas presentes, mas seriam o centro do estudo.

Há alguns currículos que indicam competências, mas são tão genéricas, tão amplas, que pouco definem. Um exemplo que pode ser citado é o da Matemática Financeira, presente nos Cursos de Administração: a competência "conhecer juros simples e juros compostos" é frequente. Embora possa ser vislumbrado o significado dessa competência, deve-se reconhecer que essa é muito vaga: diferenciar juros simples de juros compostos, incluindo a resolução de problemas com essas duas modalidades de juros? Essa indicação pode estar implícita, dependendo do leitor, mas em quais situações, problemas escolares ou em situações reais do mercado financeiro? Essa competência inclui, por exemplo, o estudo de empréstimos para comprar bens a médio ou longo prazo?

A concepção de currículo por competências, em um curso profissional, deveria ter como princípio a análise de situações concretas - tão próximas o quanto possível da realidade profissional - e a definição das habilidades necessárias para resolvê-las, indicando objetos de conhecimento requeridos, em vez de ter como ponto de partida um corpo tradicional de conteúdos disciplinares.

O eixo horizontal das figuras a seguir está relacionado 
aos objetos de conhecimento/conteúdos e o sentido da seta indica a progressão de complexidade em relação ao tempo, representado pelo eixo inclinado; o vertical se refere às competências, às habilidades e às aplicações e o sentido da seta também mostra progressão. Cabe destacar que os três termos desse eixo - competências, habilidades, aplicações significam complementaridade de significados.

Assume-se a pressuposição de que a implementação de um currículo, cujo foco é o desenvolvimento de competências, é mais complicado que a de um currículo centrado apenas no ensino de conceitos. Essa posição se fundamenta na longa tradição brasileira de valorizar os conteúdos disciplinares, sem atentar, muitas vezes, às necessidades de modificá-los ao longo do tempo. A Figura 1 explicita essa posição.

Figura 1 - duas modalidades de currículo

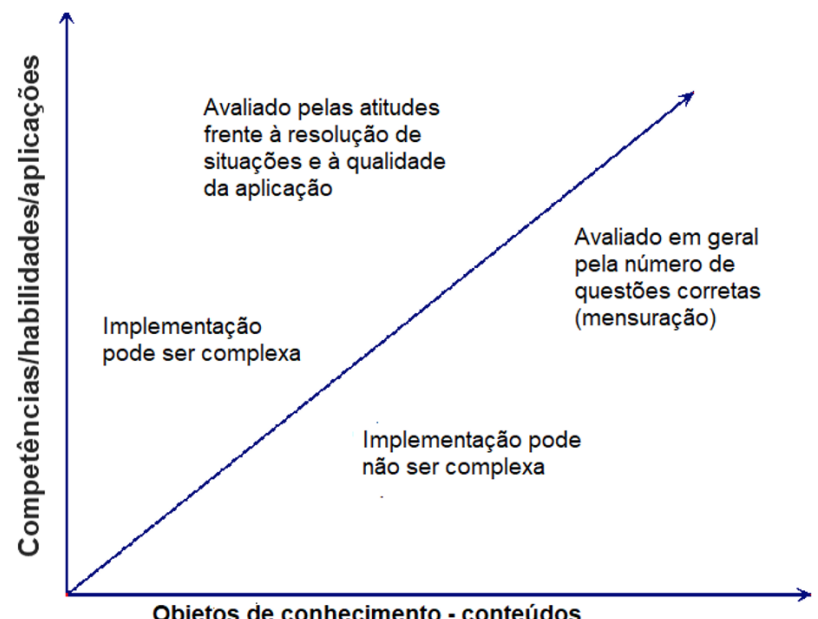

Fonte: Os autores.

As avaliações dos processos de ensino e aprendizagem nessas duas modalidades de currículo seriam distintas. Os estudantes de cursos, cujos currículos se baseiam no ensino de conteúdos disciplinares, são avaliados, geralmente, por meio de provas e de exames, contabilizando acertos.

Uma formação, cujo pressuposto é o desenvolvimento de competências, prevê que no currículo em ação sejam propostos aos estudantes situações, que exijam aplicações de esquemas operatórios, compreendendo significados e como funcionam. Esse fato implica em não promover a dicotomia entre o saber e o saber-fazer e sim promover aprendizagens para atingir uma integração entre ambos.

Em um currículo por competências, as avaliações deveriam ser mais qualitativas, pois além de avaliar os conhecimentos de conceitos e as habilidades em aplicá-los - o saber fazer seria importante analisar as atitudes do estudante ao realizar uma tarefa: o desenvolvimento da capacidade de investigação e da perseverança na busca de resultados; a valorização do trabalho coletivo; a predisposição para se informar de inovações profissionais e analisá-las; a valorização do uso de aplicativos e softwares como ferramentas, que auxiliam na realização das tarefas profissionais, sem anular o esforço da atividade compreensiva, entre outras.
O mundo do trabalho analisa o que os egressos das Universidades conseguem fazer com os conhecimentos que têm. Esse fato indica claramente que as Universidades precisam, cada vez mais, atentar ao mercado. A figura 2 pode representar uma síntese do que se disse até aqui.

Figura 2 - Comparação entre as duas modalidades

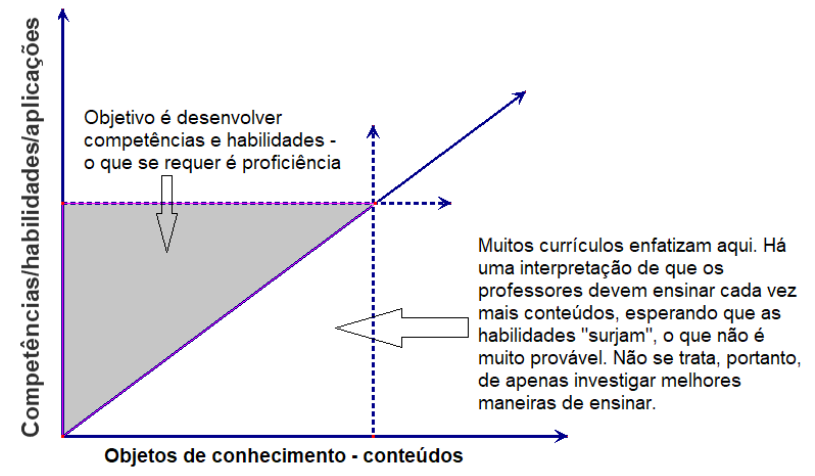

Fonte: Os autores.

Mediante a breve apresentação de questões sobre um currículo por competências, na Educação Superior, é necessário indicar a questão da flexibilidade desses currículos de modo a atender as especificidades não apenas de um público jovem, mas também de adultos com diferentes experiências, desde aqueles que já trabalham na área do curso até para os que estão migrando de área. Portanto, é preciso pensar em aprendizado personalizado.

O ressurgimento do estudo independente e individualizado deve ser conduzido e facilitado pelas mais avançadas técnicas e tecnologias pedagógicas de ponta como aplicativos, simuladores, gamificação e recursos educacionais abertos. Para Moore (2016), esse estudo depende muito de capacidade da instituição em promover a interação estudante - estudante em seu sistema multimídia e multitalentoso.

\subsection{Conhecimentos, Competências e Formação de professores}

Neste artigo se parte do pressuposto de que os significados de Conhecimento e Competência não são exatamente equivalentes. O desenvolvimento de competências não se pode confundir com a construção de conhecimentos. No entanto, uma competência não é desenvolvida sem haver aprendizagens de conhecimentos e sem colocá-los em ação.

Valorizar as competências nunca poderá significar esquecer, nem mesmo subalternizar, outras justificações dos saberes. Tal valorização exige, poder-se-á afirmar que determina, a explicitação das razões da seleção dos saberes sujeitos à aprendizagem. Reforçar as competências não é uma ruptura com os conhecimentos, será, antes, uma evolução na relação com o conhecimento, no sentido de o justificar e encontrar a verdadeira dimensão formativa do saber que dele decorre (GASPAR, 2004, p.63).

Para Perrenoud (1998), a questão do desenvolvimento de competências nas instituições escolares não deveria ser considerada mais um modismo, mas sim um retorno às 
origens, às finalidades dessas instituições.

Reitera-se a existência de um consenso quanto à organização de um currículo referenciado em competências, quando se concebe a formação profissional, pois é difícil defender a ideia de um processo formativo, baseado apenas em conhecimentos teóricos. Todavia, é importante ressaltar que um bom profissional não é apenas aquele que age com pertinência em situações específicas, mas também compreende o porquê e como age.

A docência é considerada uma profissão e o profissional que a desempenha é denominado por professor. Suas competências profissionais se constroem não apenas em formação inicial ou continuada, mas também por meio de sua prática diária de uma situação de trabalho à outra.

Perrenoud (1999) destaca dez grandes famílias de competências, que deveriam nortear as formações docentes. Entre essas estariam as concernentes às aprendizagens como a de organizar e dirigir situações de aprendizagem e, também, as atinentes à administração de sua própria formação contínua, explicitando as próprias práticas ou identificando seu próprio repertório de competências e de programa pessoal de estudos. Assim, esse autor destaca as competências emergentes, que advém de práticas inovadoras, aquelas que contribuem para a luta contra o fracasso dos estudantes, aquelas que recorrem à pesquisa e enfatizam a prática reflexiva do professor.

Desse modo, a formação de um docente, como a de qualquer outro profissional, inclui necessariamente a sua preparação inicial e a que dá continuidade a esta primeira formação, atualizando-a e reorientando-a para o que habitualmente é nomeada de formação ao longo da vida.

Portanto, pode ser determinante que o desenvolvimento de competências na formação de professores, seja condição imprescindível à abordagem curricular por competências.

\section{Conclusão}

As Instituições de Ensino devem estar atentas aos níveis educacionais requeridos das pessoas, cada vez mais exigentes, pelo mundo do trabalho. Hoje, a sociedade exige dos profissionais competências mais amplas, ou mais sofisticadas para enfrentar os desafios profissionais, demandando uma aprendizagem permanente, ao longo de toda a vida, em decorrência do processo contínuo de produção do conhecimento.

Em relação às competências, muitas questões têm sido discutidas, sobretudo, quanto a sua relação com as finalidades e objetivos do currículo, com o conhecimento e com o mercado de trabalho. Parece fundamental que haja uma reflexão acerca deste conceito, não apenas quanto às significações que lhe são atribuídas, mas igualmente sobre as consequências que podem trazer para as práticas dos professores.

O currículo por competências, que também pressupõe um sistema multidimensional de ensino, implica necessariamente em uma reinvenção do papel do professor, distanciando-se de um modelo convencional "professor da sala de aula" para se tornar membro de um grupo multitalentoso.

Defende-se que entre as competências desse professor se deve incluir a de saber criar centros de interesse para os alunos adultos, explorando situações de aprendizagem em torno das quais organizará os objetos de aprendizagem expressos nas competências profissionais a serem desenvolvidas. Assim, o docente deverá estimular o estudante a fazer investigações, de fazer perguntas, bem como de orientar e depurar interesses relevantes, assumindo, com tolerância, a responsabilidade inerente à função que exerce.

Em síntese, os professores do Ensino Superior devem ser capazes de mobilizar estratégias diversificadas e promover inovações, tendo em vista o desenvolvimento das competências pessoais e profissionais dos estudantes adultos, caracterizadas pela capacidade de expressão, enfrentamento de situações-problema em contextos profissionais - tão reais o quanto possível.

\section{Referências}

BRASIL. Ministério da Educação. Base Nacional Comum Curricular - Educação é a Base: Ensino Fundamental. Brasília: MEC, 2018.

BRASIL. Ministério da Educação. Conselho Nacional de Educação. Parecer 583/2001. Disponível em: http://portal.mec. gov.br/cne/arquivos/pdf/rces004_05.pdf. Acesso em: 8 set. 2020.

GASPAR, M.I. Competências em questão: contributo para a formação de professores. repositorioaberto.uab.pt, 2004.

MACEDO, L. Competências e habilidades: elementos para uma reflexão pedagógica. 2005. Disponivel em: http://www. rededosaber.sp.gov.br/portais/Portals/18/arquivos/competencias na_educacao_cr.pdf

MOORE, M.G. Flipped classrooms, study centers andragogy and independent learning. Am. J. Dist. Educ., 2016.

PACHECO, J.A. Descentralizar o discurso curricular das competências. Rev. Estud. Curriculares, v.3, n.1, p.65-92, 2005.

PERRENOUD, P. Desenvolver competências ou ensinar saberes? A escola que prepara para a vida; . Porto Alegre: Penso, 2013.

ROLDÃO, M.C. Gestão do currículo e avaliação de competências: as questões dos professores. Barcarena: Editorial Presença, 2003.

SEVERINO, A. J. Metodologia do trabalho científico. São Paulo: Cortez, 2007. 